Article

\title{
Continuous Improvement Process in the Development of a Low-Cost Rotational Rheometer
}

\author{
Francisco J. Hernández-Rangel ${ }^{1}$, María Z. Saavedra-Leos ${ }^{1}{ }^{\circledR}$, Josefa Morales-Morales ${ }^{1,2}{ }^{\circledR}$, \\ Horacio Bautista-Santos ${ }^{2,3}{ }^{\mathbb{D}}$, Vladimir A. Reyes-Herrera ${ }^{4}{ }^{\circledR}$, José M. Rodríguez-Lelis ${ }^{5}$ and \\ Pedro Cruz-Alcantar $1, *$ (D) \\ 1 Coordinación Académica Región Altiplano, Universidad Autónoma de San Luis Potosí, Carretera Cedral \\ Km, 5+600 Ejido San José de las Trojes, Matehuala, San Luis Potosí 78700, Mexico; \\ josue.hernandez@uaslp.mx (F.J.H.-R.); zenaida.saavedra@uaslp.mx (M.Z.S.-L.); \\ josefa.morales@uaslp.mx (J.M.-M.) \\ 2 Tecnológico Nacional de Mexico/ Instituto Tecnológico Superior de Chicontepec, Calle Barrio Dos Caminos \\ No. 22. Colonia Barrio Dos Caminos, Chicontepec, Veracruz 92709, Mexico; horacio.bautista@itsta.edu.mx \\ 3 Tecnológico Nacional de México/ Instituto Tecnológico Superior de Tantoyuca, Desviación Lindero Tametate \\ S/N, Colonia La Morita, Tantoyuca, Veracruz 92100, Mexico \\ 4 Instituto de Energías Renovables, Universidad Nacional Autónoma de Mexico, Priv. Xochicalco s/n, \\ Col. Centro, Temixco, Morelos 62580, Mexico; Varh@ier.unam.mx \\ 5 Tecnológico Nacional de Mexico/Centro Nacional de Investigación y Desarrollo Tecnológico, Interior \\ Internado Palmira S/N, Col. Palmira, Cuernavaca 62490, Mexico; jmlelis@cenidet.edu.mx \\ * Correspondence: pedro.cruz@uaslp.mx
}

Received: 2 July 2020; Accepted: 30 July 2020; Published: 3 August 2020

\begin{abstract}
The rheological characterization of fluids using a rheometer is an essential task in food processing, materials, healthcare or even industrial engineering; in some cases, the high cost of a rheometer and the issues related to the possibility of developing both electrorheological and magnetorheological tests in the same instrument have to be overcome. With that in mind, this study designed and constructed a low-cost rotational rheometer with the capacity to adapt to electro- and magneto-rheological tests. The design team used the method of continuous improvement through Quality Function Deployment (QFD) and risk analysis tools such as Failure Mode and Effect Analysis (FMEA) and Finite Element Analysis (FEA). These analyses were prepared in order to meet the customer's needs and engineering requirements. In addition to the above, a manufacturing control based on process sheets was used, leading to the construction of a functional rheometer with a cost of USD $\$ 1500$.
\end{abstract}

Keywords: rheometer; quality function deployment; design

\section{Introduction}

Rheology studies stress and deformation of matter that may flow, not only including liquids but also soft solids and substances such as sludge, suspensions, and human body fluids, among others [1,2]. Rheology focuses on the study of fluids, with viscosity changing when the material deforms or is submitted to certain external forces or agents, such as electric fields, magnetic fields, temperature, pressure, light, and $\mathrm{PH}$, among others. Within fluids using rheological properties for very specific applications, we have magneto- and electro-rheological fluids [1,3]. Magneto-rheological fluids are smarts fluid containing particles that orient themselves and form chains in the presence of a magnetic field. In turn, electrorheological fluids are suspensions that do not conduct electricity; these fluids are known as dielectric, and when an electric stimulus is applied to these materials, some of their mechanical properties may be controlled [1-4]. A basic instrument for the study of rheological properties 
is the rheometer. A rheometer is capable of measuring the viscosity and elasticity of Newtonian and non-Newtonian materials in a wide range of conditions. Some of the properties that may be measured with a rheometer are viscoelasticity, elasticity limit, thixotropy, and extensional viscosity [1,5]. Rheology has wide applications in industry, in research, and in the development of products-for example, in the evaluation of paints, creams, and plasters; in healthcare; and in aeronautical and automotive applications [6-13]. A particular application in automobiles is in rheological dampers found in suspension systems that allow the adjustment of the mechanism of operation in accordance with the vehicle's needs $[13,14]$. In order to make the necessary operation adjustments, modern automobiles have sensors which enable the detection of road conditions, measuring the power of rebounds experienced in the suspension. Among the advantages of using suspensions based on rheological dampers is their low energy requirement. In addition, the system is reliable, and there is dynamic control of the whole automobile [15]. This last application is part of the motivation for this work, since having a rheometer would greatly help the characterization of rheological fluids. Currently, there are rheometers of varying kinds and prices [16], but most of them have a high cost and may only be used for very specific tests, and do not allow, for example, electrorheological and magnetorheological tests to be carried out on the same rheometer. This study presents the design and development of a low-cost rotational rheometer with the capacity to couple to any necessary instruments in order to carry out electro- and magneto-rheological tests. The proposed methodology considers continuous improvement processes in the design of new products widely used in the industrial and development sector-specifically, the use of the Quality Function Deployment (QFD) tool based on customer satisfaction and cost reduction [17-29], supported with Failure Mode and Effect Analysis (FMEA) risk detection tools [30-34], Finite Element Analysis (FEA) engineering analyses, and manufacturing processes. With the methodological process used, the design and construction of a functional rheometer was possible with a cost of USD \$1500 with the capacity to adapt for electro- and magnetorheological tests.

\section{Methodology}

The methodological process for the design and manufacturing of the rheometer is shown in the following Figure 1.

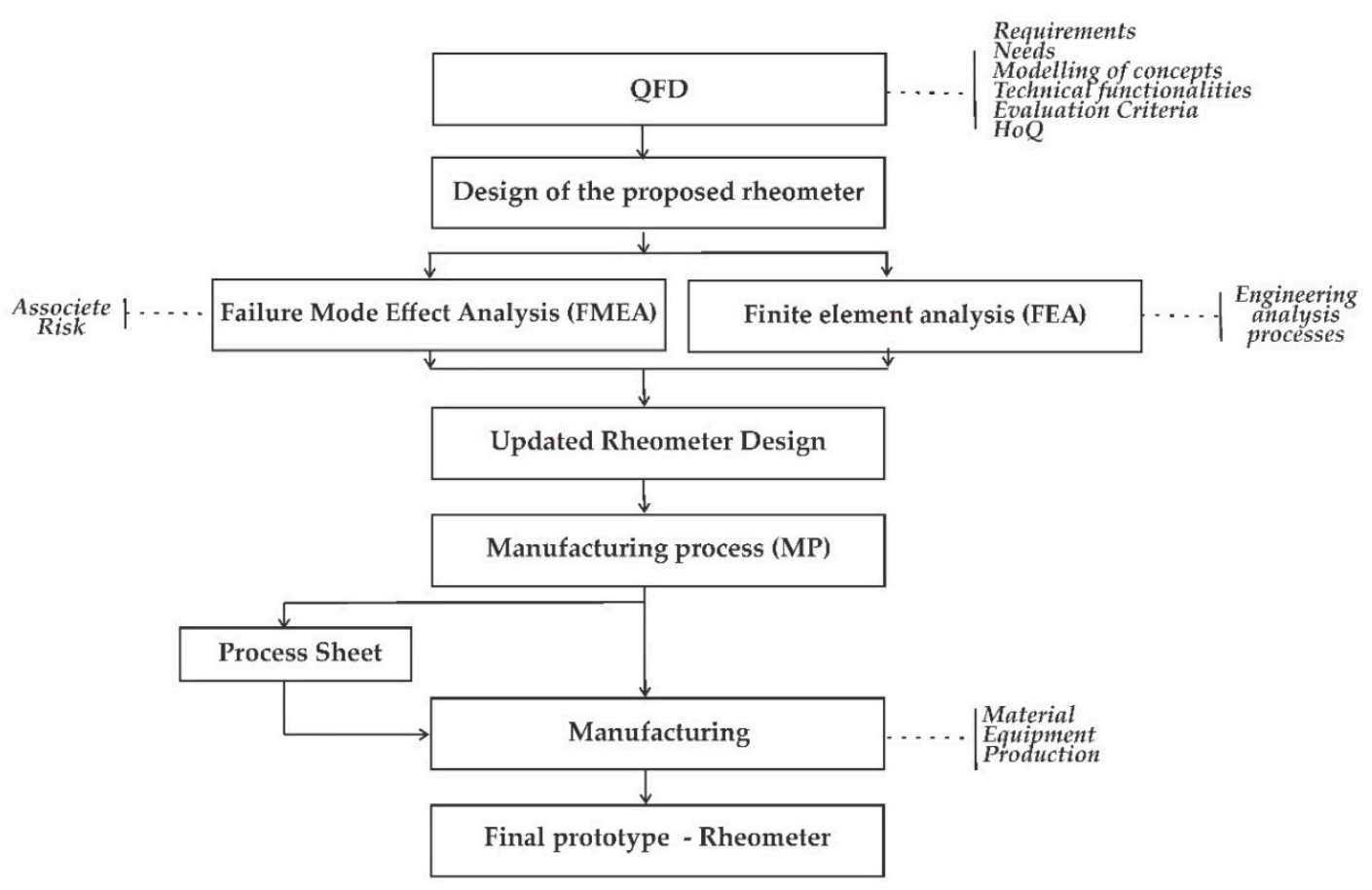

Figure 1. The methodological process. 
Steps within the methodology consider the initial phase with the QFD development and the HoQ (House of Quality), where the customer requirements and the technical specifications are taken as baselines in order to design the rheometer. With the above in mind, an initial design for the rheometer is proposed to pass afterwards for a risk analysis using the FMEA technique and the analysis of finite elements (FEA). The purpose is to provide feedback on the proposed design to generate an updated final design. The last phase deals with the assurance of the manufacturing process (MP), where a tool called the process sheet was used to control activities related to the manufacturing process and finally to obtain the rheometer prototype.

\subsection{Quality Function Deployment (QFD) and House of Quality (HoQ)}

QFD is a method to transform users' qualitative demands into quantitative parameters, thus achieving design quality in subsystems and pieces and ultimately in the specific elements of the manufacturing process. The method was developed in 1966 in Japan and represented the impulse for the continuous improvement of products seeking optimization and rationalization in the design of its products and processes [17]. QFD is a systematic methodology with a priority of interpreting and meeting the customer's requirements during the design and manufacturing processes, promoting the interaction of the design actors (engineers, technicians, users, sellers, etc.) since the QFD is a group methodology [25,27]. The QFD approach is based on the deployment of users' expectations (the "What's") in terms of the design and parameters related to the production (the "How's") of the new product. This process is represented by a succession of double entry or matrix tables of "What/How", allowing correlations between the entries to be identified and prioritized [27]. A crucial step during QFD is the translation of the customer' needs into engineering characteristics [18].

\subsubsection{Customer Requirements}

Requirements are customers' declared and undeclared needs, demands, or wishes. Identifying customer requirements is considered critical to achieving effective and successful processes in product development at the design stage [35]. In some works, requirements are reported within the preliminary design stage as the formulation or decomposition of requirements $[35,36]$. The design and development department faces the problem of identifying the requirements in order to obtain a list of needs that will lead to the success of the design project development [37]. Customer, user, or market demands are captured in different ways: direct discussion or interviews with potential customers, surveys, focus groups, customer specifications, observation, warranty data, field reports, etc. [24]. One way to obtain simple information is through an interview, applying the method of the Five W1H (Who, What, Why, How, Where, When). The respondents can be a small number of people or even individuals among current customers, competing customers, and direct users in the same market segment [38].

\subsubsection{House of Quality (HoQ)}

QFD implies the construction of a matrix or a set of interconnected matrices known as "quality tables". The first matrix is called "House of Quality" (HoQ) and has two main parts: the horizontal part, containing information relevant for the customer, and the vertical part, containing the corresponding technical translation of their needs. In addition, there are the "What/Which" correlations, which allow the integration of elements related to the analysis of product competence and the identification of contradictions between different product characteristics [25]. Thus, this matrix offers the double advantage of facilitating the transition between the user world and the designer, in order to combine in one document all the data for decision making in relation to the development of the product. Commonly, the design teams have to base their estimations on their own experience, intuition, and determination [18].

Figure 2 presents the components of the HoQ, which are: customer requirements, technical parameters, relationship matrix, engineering importance, numerical values of the parameters, 
correlation matrix between the technical parameters, customer benchmarking, technical benchmarking, and technical importance [24].

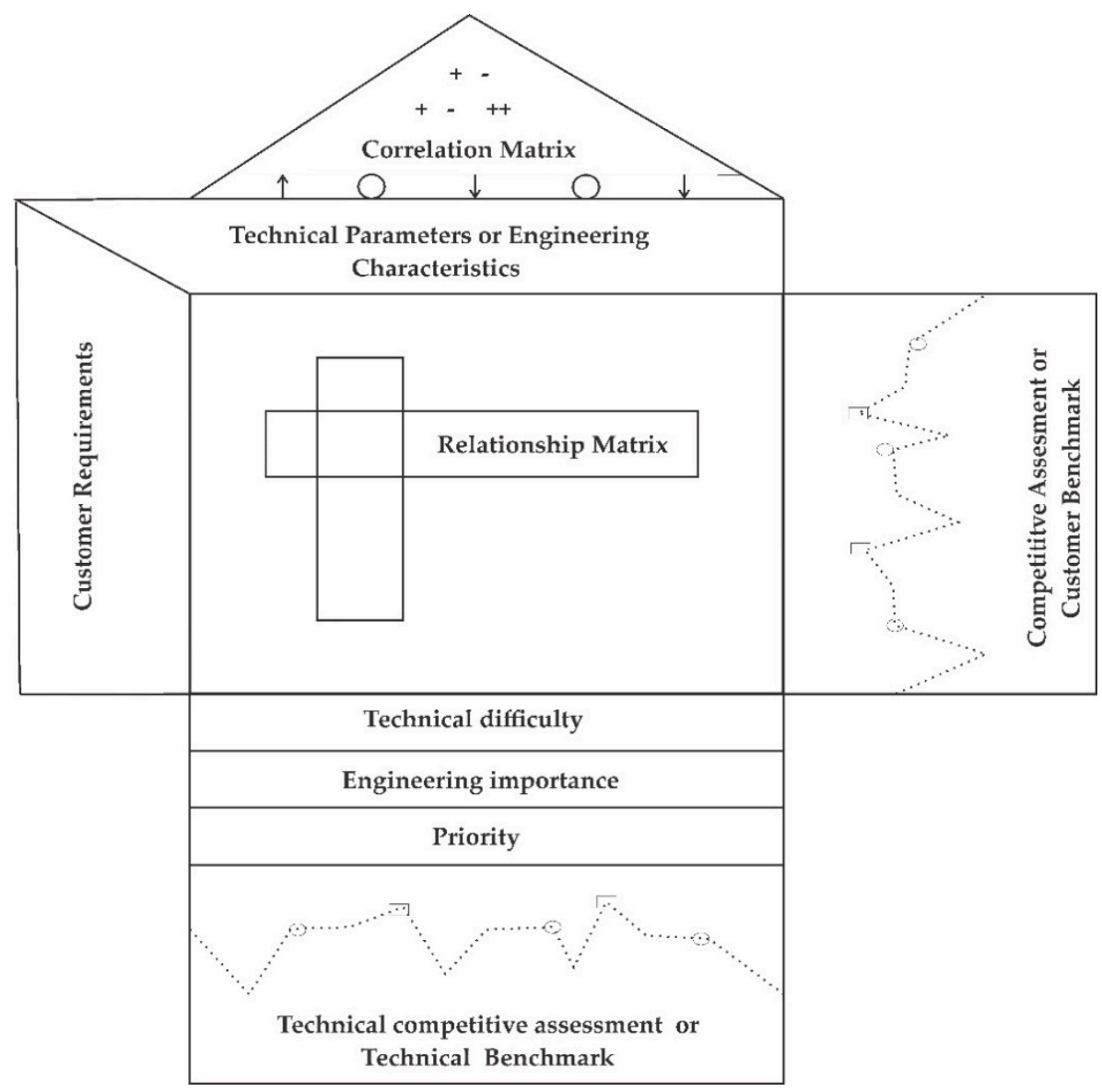

Figure 2. House of Quality (HoQ) and components.

The results expected after applying QDF through the House of Quality are the following [24]:

1. Document the environment in which the product is used (needs).

2. Classify needs in a logical order and evaluate the relative importance therof.

3. Understand customer's needs as summarized in the planning of the product, matrices, or House of Quality.

4. Identify the technical requirements directly influencing satisfaction needs in order to formulate complete technical specifications.

Commonly, the QFD is supported by several methods to improve its effectiveness, such as the TRIZ (the Russian acronym of the Theory of Inventive Problem Solving) [39,40], FMEA (Failure Mode, Effect, and Analysis), FTA (Failure Tree Analysis) [41], and diffuse theory, among others [21,28].

\subsection{Failure Mode Effect Analysis (FMEA) and Finite Element Analysis (FEA)}

FMEA is an analytic technique used to identify, reduce, or eliminate negative effects of the failure methods of a product, design, service, or process and its relevant causes before they are produced [22]. The technique functions by means of the identification of a concrete cause of failure mode within a system, such that the logical sequence of this condition is traced through the system up to the final effects [25]. Risk assessment is based on the occurrence, severity, and detection of a possible failure; therefore, it focuses on potential failures and not on the failures produced, as the objective is to prevent failures from occurring. The main idea is to generate a risk priority number (RPN) for each failure 
mode; the higher the risk number, the greater the potential risk and importance of addressing this failure mode [30].

FMEA improves the operational performance of production cycles and reduces the risk level. When using the FMEA, the risk is calculated in relation to three coefficients: the seriousness of the non-conformity $(S)$, the non-conformity occurrence frequency $(O)$, and the detectability of the non-conformity $(D)$. Each coefficient is assigned a value ranging from 1 to 10, and the relative risk index is calculated $(R)$ as shown in the following equation [30]:

$$
R P N=D \times O \times S .
$$

The values of parameters $O, S$, and $D$ are taken from the tables provided by the method and are shown below in Table 1.

Table 1. $D, O$, and $S$ evaluation criteria.

\begin{tabular}{cccccc}
\hline $\boldsymbol{D}$ Value & Detection & $\boldsymbol{O}$ value & Occurrence & $S$ Value & Severity \\
\hline 1 & Almost certain & 1 & Extremely Unlikely & 1 & None \\
\hline 2 & Very High & 2 & Unlikely & 2 & Very Slight \\
\hline 3 & High & 3 & Minimal & 3 & Minimal \\
\hline 4 & Moderately high & 4 & Very Slight Probability & 4 & Minor \\
\hline 5 & Moderate & 5 & Slight Probability & 5 & Moderate \\
\hline 6 & Low & 6 & Low Probability & 6 & Serious \\
\hline 7 & Very low & 7 & Medium Probability & 7 & Very Serious \\
\hline 8 & Remote & 8 & Moderately High Probability & 8 & Extremely Serious \\
\hline 10 & Very remote & 9 & High Probability & 9 & Hazardous \\
\hline
\end{tabular}

A scale proposed to quantify the severity of a failure using the RPN is presented below in Table 2 .

Table 2. Risk priority number (RPN) criteria.

\begin{tabular}{cll}
\hline RPN & Severity & \multicolumn{1}{c}{ Description } \\
\hline RPN $<\mathbf{5 0}$ & Minor & $\begin{array}{l}\text { This mode of failure can be detected by the company; it means a simple change in } \\
\text { the design, unless the mode of failure is included in the standard. }\end{array}$ \\
\hline $\mathbf{5 0}<\mathbf{R P N}<\mathbf{1 0 0}$ & Significant & $\begin{array}{l}\text { The Priority Risk Number of this failure mode can be decreased after an } \\
\text { adjustment to the design in the company's laboratories. }\end{array}$ \\
\hline $\mathbf{R P N}>\mathbf{1 0 0}$ & $\begin{array}{l}\text { Very Serious or } \\
\text { Hazardous }\end{array}$ & $\begin{array}{l}\text { This mode of failure must be reduced or eliminated through the various } \\
\text { laboratory tests that are performed, or if necessary we must change the design } \\
\text { concept. If it is not diminished, the product cannot be sold to the market. }\end{array}$ \\
\hline
\end{tabular}

FMEA is focused on predicting a possible product failure in advance in order to avoid reworking in the subsequent fabrication process, thus greatly reducing the cost of the product, shortening the cycle, and improving the manufacturing efficiency [21].

\subsection{Finite Element Analysis (FEA)}

Finite Element Analysis (FEA) is a numerical method for approximating the solutions to differential equations widely used in diverse problems-mainly for the modelling and simulation of engineering problems. FEA can be applied in stress analyses on structures or complicated machines, dynamic responses, or in thermal or electromagnetic analyses. FEA applications have also been extended to materials in science, biomedical engineering, geophysics, and many other fields [42,43].

\subsection{Manufacturing Process (MP)}

The planning process has an essential role in the manufacturing and industrial processes of home appliance and tool manufacturing and chemical processing plants. Planning a manufacturing 
process is transforming a portion of the design into specifications from the drawing plans in the operation instructions needed for manufacturing [44]. The planning of a manufacturing process may be defined as the systematic determination of the detailed methods with which components or parts may be economically manufactured from the initial stage to the end stage. Geometric characteristics; dimensions; tolerances; materials; and, finally, the sequence of operations, machinery, tools, and work stations are analyzed to obtain the desired final product. The first task of the planning process implies a series of steps: design data interpretation (CAD); understanding the functions, conditions, and product specifications; and carefully analyzing any assembly operations that are to be performed $[44,45]$. All the above may be found on a manufacturing process sheet.

\section{Process Sheet}

Process planning is a pre-manufacturing step which determines the sequence of operations or processes necessary to produce a part or a set. This is the most important step in workshops where unique products are manufactured or where the same product is manufactured infrequently. The result of this step is the process sheet, which considers the route and operations data [44,45]. A process sheet is a document listing the exact sequence of operations needed to complete the job. The route sheets are useful in manufacturing and production planning. An example of a process sheet is found in Table 3.

Table 3. Typical process sheet.

\begin{tabular}{|c|c|c|c|c|c|c|c|c|}
\hline \multirow{2}{*}{$\begin{array}{c}\text { Process Capacity } \\
\text { Sheet }\end{array}$} & \multirow{2}{*}{$\begin{array}{c}\text { Approved } \\
\text { by: }\end{array}$} & \multicolumn{3}{|c|}{ Part No. } & \multicolumn{2}{|c|}{ Application } & Entered by: & Date: \\
\hline & & \multicolumn{3}{|c|}{ Part Name: } & \multicolumn{2}{|c|}{ Number of Parts } & \multicolumn{2}{|c|}{ Line: } \\
\hline \multirow{2}{*}{ Step Name } & \multirow{2}{*}{ Machine } & \multicolumn{3}{|c|}{ Basic Time } & \multicolumn{2}{|c|}{ Tool Change } & Processing & Romarke \\
\hline & & Manual & Auto & Completion & Change & Time & Capacity/Shift & Nemarks \\
\hline
\end{tabular}

\section{Results}

For the QDF development, we had the criteria of 12 participants, among whom were laboratory technicians, researchers, vendors, and designers who have used a rheometer at some time or have been connected to rheological tests. The process of acquiring the requirements consisted of the participation of the working group in discussions and interviews and the analysis of direct specifications for the rheometer design by a research group on intelligent fluids. In addition to the above, an extensive search of patents and scientific articles was carried out in order to explore the data reported on operation issues, components, and requirements, and, in turn, it was complemented by a market study on commercial rheometers. The criteria analyzed were the overall features, operation, aesthetics, ergonomics, measurement schemes, man-machine environments, and costs, among others. With the information found, the determination of the customer's needs and requirements was possible, as shown in Table 4. For each of the requirements considered, a quantified weight is assigned in order to prioritize them and define which ones will be of priority in the design stage. The scales to qualify the weight of requirements vary according to each author; in this case, significance values were proposed from 5,3 , and 1 , where 5 is for the highest significance and 1 for the lowest significance [30].

Table 4. Customer requirements and their importance.

\begin{tabular}{cccc}
\hline Customer Requirements & Importance or Weights & Customer Requirements & Importance or Weights \\
\hline Easy to use & 5 & Minimum error margin & 5 \\
\hline Display results on an LCD display & 5 & Use with any fluid-electro and magnet & 3 \\
\hline Economic & 3 & Store data & 3 \\
\hline Aesthetic & 3 & Automatic calculations & 5 \\
\hline Small size & 3 & Easy to manufacture & 5 \\
\hline Strong and lightweight & 1 & Secure & 5 \\
\hline Portable & 5 & Easy maintenance & 5 \\
\hline \multicolumn{2}{l}{}
\end{tabular}




\subsection{Technical Requirements}

In this section, the work team translates the customer's needs into an engineering language that is direct and easy to interpret; this is done in order that the designers may have clearly defined, in the design stage, clearly defined parameters and properties to be included in the modeling stage. Figure 3 shows the technical requirements translated into engineering language. In addition, the right side of the figure shows the relationships between the technical requirements and what will be taken as criteria for the design team's decision making.

\begin{tabular}{l}
\hline Equations and calculations in one program \\
\hline 8 line by 16-character display-LCD \\
\hline Electric power supply 110 \\
\hline Black pigment- $\mathrm{LCD}$ \\
\hline Size $: 20 \times 25 \times 40 \mathrm{~cm}$ \\
\hline Materials: Nylamid, Acrylic, Aluminium and Steel \\
\hline $12 \mathrm{~V}$ Rechargeable Battery (electronic accessories) \\
\hline Structure with a minimum of components (approximately 11 parts) \\
\hline Six digits of accuracy
\end{tabular}

Figure 3. Technical or engineering requirements.

After the customers' requirements and technical requirements had been identified, the design team proposed the following correlations for the "What" /"How" between each of the customer's needs and each engineering characteristic, where 5 is a strong correlation, 3 is a moderate correlation, and 1 is a weak correlation. After this, estimations were compared among them. Once the significance values and the correlation values were defined, the absolute significance value is calculated $(B)$ as the sum of the customer evaluation product multiplied by the weight corresponding to the degree of dependence [20].

$$
B=\sum(I \times R)
$$

The result is provided at the bottom of the column and shows the significance of the requirement-that is, the priority quality characteristics for a customer.

\subsection{Competitive and Technical Comparison Evaluation (Customer benchmarking-Technical benchmarking)}

The QFD tool through the House of Quality allows direct comparison of how its design or product ranks against the competition in fulfilling customer requirements. This analysis is very important in making decisions related to design, considering that a certain type of scale is essential to describe the excellence level of these products and our product, in order to find the route to achieve customer satisfaction. The design team, with the contribution of all its members, identifies a series of existing products to be compared-usually the proposed product and two or three of the relevant competitors $[23,27]$. One of the purposes of this stage is to know how the competitors' products compare to the customers' requirements compared to the product proposed by the design team. In order to carry out the competitive evaluation, four commercial rheometers were taken into consideration: HAAKE RheoStress 6000, HAAKE MARS Rheometer, ARES-G2 Rheometer, and Kinexus lab+ rheometer. Once the competitors are identified, a table is generated with the customer's requirements met by each of the competitors and the design team's proposal using a five-level scale where $1=$ very low satisfaction and $5=$ very high satisfaction [23]. Once the above points are obtained, the House of Quality is obtained for the design of the rheometer proposed by the design team. The House of Quality is shown in the Figure 4. 


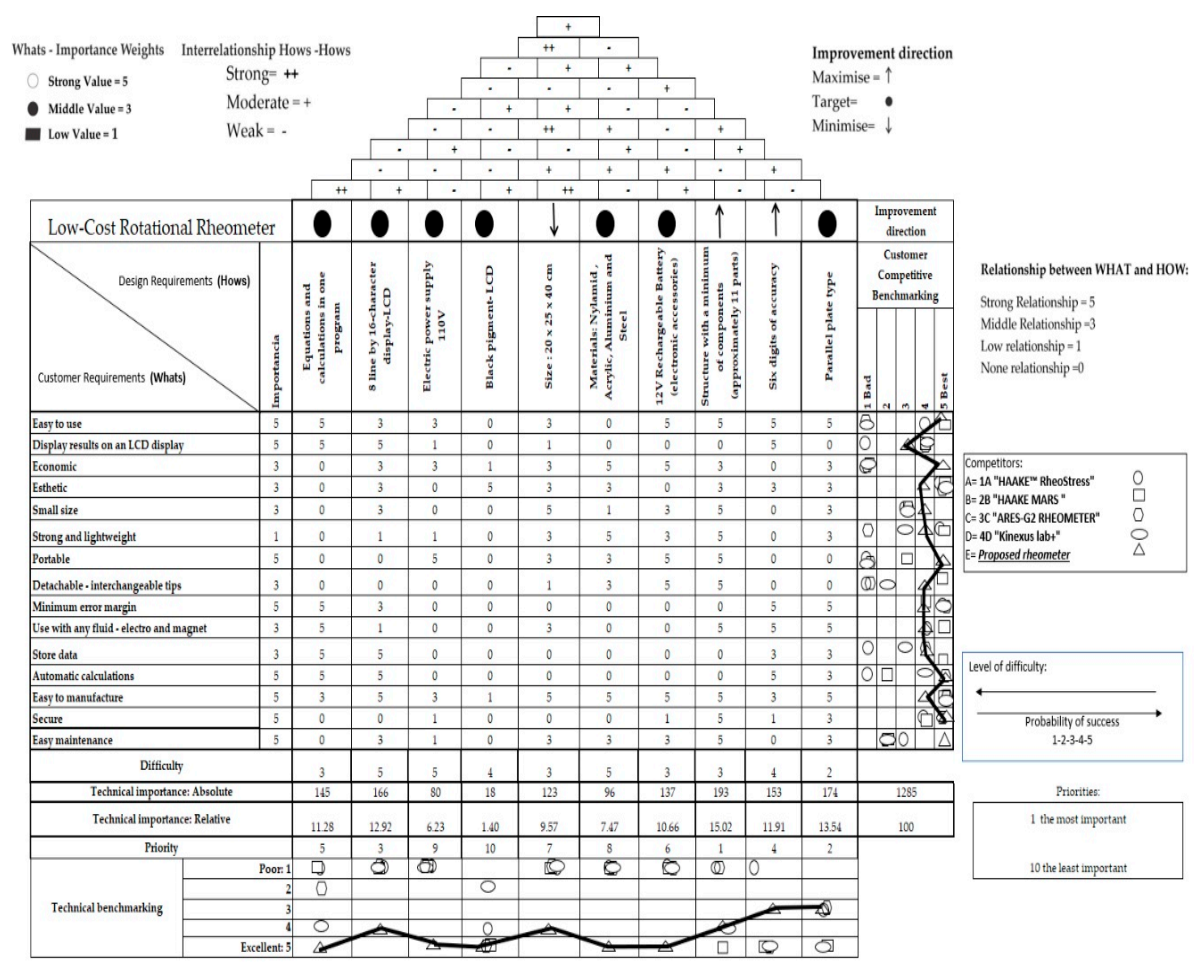

Figure 4. House of Quality (HoQ)—low cost rheometer.

In the last QFD analysis section, the importance of all the customer requirements and the contribution of each technical requirement to meeting said requirements are analyzed. This final analysis is crucial for design, as this is where the information obtained in the evaluations of the other matrices is gathered and the result of each technical requirement is evaluated and finally reordered, before proceeding to the design. From the House of Quality results, especially the results of absolute technical importance $(B)$ and priority, it is clear that some requirements are of greater importance than others. This is closely related to the methodology, but in spite of its score, all the requirements are met and included in the design generated by the work team. From the technical importance results, the following can be concluded:

(1) The technical requirement of minimal parts obtained a high importance index of 193 and a priority order of 1 . This means that the proposed design must meet the minimal necessary elements for rheometer operation; this requirement also impacts the ease of maintenance required during its lifecycle.

(2) The technical requirement of parallel plates obtained a high importance index of 174 and a priority order of 2. This technical requirement depends on how the rheological tests are carried out and the condition of the rheometer's accessories.

(3) The technical requirement for the use of an 8-line display obtained a high importance index of 166 and a priority order of 3 . This technical requirement mainly affects how the rheometer user will interact with the variables that must be measured during the rheological tests.

Finally, we would obtain the remaining features, where the feature with the lowest priority is the use of dark pigments for display data, among others. The competitive and technical evaluation had the purpose of analyzing similar products which were already on the market in order to produce a rheometer with qualities not lower than those of competitors. As may be observed regarding quality in the competitive and technical evaluation section, the designing team proposal was always within a margin superior to the competition in most aspects. This shows that our product will be superior to or will keep customers much more satisfied than products existing on the market, 
since the proposed rheometer has a better score than the competition regarding the engineering and customers' requirements.

\subsection{Preliminary Design}

Once the House of Quality evaluation is complete, we proceed to the section on preliminary prototype design according to the House of Quality-QFD requirements. The design concept proposal has been established in a simple, intuitive approach based on the design team's experience, with the following stages: (i) the identification of the problems associated with satisfying customer requirements; (ii) the identification of the associated problems and the satisfaction of technical or engineering requirements; (iii) the acquisition of knowledge and foundations for the proposal of solutions; (iv) the proposal of design solutions; (v) the proposal of critical elements of operation, structure, and materials; (vi) the proposal of a measurement and control environment; (vii) the evaluation of the design proposal in terms of the functionality and the requirements to be met; and, finally, (viii) the preliminary rheometer design. The Figure 5 shows the exploded CAD model of the rheometer designed by the work team.

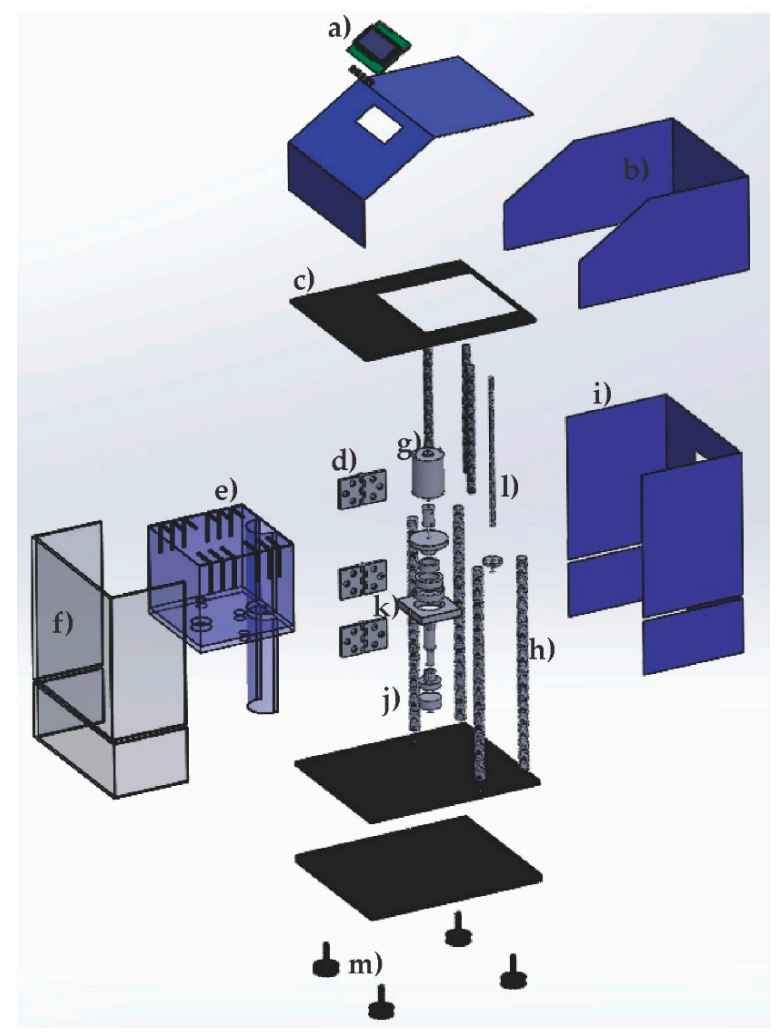

Figure 5. Design of the proposed rheometer and components. (a) LCD display; (b) sheet metal casing; (c) steel plates; (d) ball bearing hinge; (e) container box (the motor and electronic accessories); (f) acrylic protective cover; (g) motor; (h) steel rods; (i) galvanized sheet; (j) shaft, tip, and sample container assembly; (k) Nylamid couple, inertia flywheel, Nylamid bearing holder, and bearing assembly; (1) threaded rod; and (m) adjustable leg leveler.

Tables 5 and 6 show the complete FMEA format carried out in accordance with the procedure specified in the methodology section with the objective of analyzing the designed rheometer components, broken down into the parts considered critical. In accordance with the FMEA, each part of the rheometer is related to its possible potential failures. This will facilitate the identification and reinforcement of those areas where failures may occur, along with their correction, before creating the prototype. It will also provide its possible effects to provide design controls, as foreseen by the work team as a whole. 
Table 5. Failure Mode and Effect Analysis (FMEA)—low-cost rheometer: mechanical components.

\begin{tabular}{|c|c|c|c|c|c|c|c|c|c|}
\hline Item & Potential Failure Mode & Potential Effects & $s$ & Potential Causes of Failure & $o$ & $\begin{array}{l}\text { Current Controls for } \\
\text { Prevention }\end{array}$ & $D$ & RPN & Recommended Actions \\
\hline \multirow{4}{*}{ Motor } & Damage to the motor armature & Component failures & \multirow{4}{*}{10} & Motor overload & \multirow{4}{*}{8} & \multirow{4}{*}{$\begin{array}{l}\text { Inspection and preventive } \\
\text { maintenance }\end{array}$} & \multirow{4}{*}{6} & \multirow{4}{*}{480} & $\begin{array}{l}\text { Proper maintenance and allow } \\
\text { for cooling }\end{array}$ \\
\hline & Bearing damage & Deterioration of the elements & & Excessive load, poor lubrication & & & & & Allow cooling and lubrication \\
\hline & Short circuit & $\begin{array}{l}\text { Probability of damage to the } \\
\text { other components }\end{array}$ & & $\begin{array}{l}\text { Contact with water, contact } \\
\text { between wires }\end{array}$ & & & & & $\begin{array}{l}\text { Protect from moisture, check } \\
\text { connections }\end{array}$ \\
\hline & Motor misalignment & Destruction of the components & & Sudden movements & & & & & Avoid sudden movements \\
\hline \multirow{2}{*}{$\begin{array}{l}\text { Rotor (shaft } \\
\text { and tip) }\end{array}$} & Plate misalignment & Wrong results & \multirow[t]{2}{*}{5} & $\begin{array}{l}\text { Plate friction, overloading the } \\
\text { motor }\end{array}$ & \multirow{2}{*}{2} & \multirow{2}{*}{$\begin{array}{l}\text { Preventive maintenance and } \\
\text { adjustment of components }\end{array}$} & \multirow{2}{*}{8} & \multirow{2}{*}{80} & $\begin{array}{l}\text { Check multi-directional leveling } \\
\text { (bull's eye level) }\end{array}$ \\
\hline & Gear wear & Do not rotate the shaft & & Wear due to lack of lubricant & & & & & $\begin{array}{l}\text { Preventive maintenance and } \\
\text { lubrication }\end{array}$ \\
\hline \multirow{2}{*}{ Plates } & Misleveled plates & Measurement error & \multirow{2}{*}{5} & Not having a bubble leveler & \multirow{2}{*}{2} & \multirow{2}{*}{$\begin{array}{l}\text { Preventive maintenance, } \\
\text { lubricating, and checking levels }\end{array}$} & \multirow{2}{*}{5} & \multirow{2}{*}{50} & Check multi-directional leveling \\
\hline & Loosening & Test point parallelism problems & & Poor installation of components & & & & & Checking component adjustment \\
\hline $\begin{array}{l}\text { Basis and } \\
\text { structure }\end{array}$ & Fracture of the plates & Measurement error & 5 & Fracture due to misuse & 2 & Replace component & 5 & 50 & Replace the part \\
\hline
\end{tabular}

Table 6. FMEA—low-cost rheometer: electrical and electronic components.

\begin{tabular}{|c|c|c|c|c|c|c|c|c|c|}
\hline Item & Potential Failure Mode & Potential Effects & $s$ & Potential Causes of Failure & $o$ & $\begin{array}{l}\text { Current Controls } \\
\text { for Prevention }\end{array}$ & $D$ & RPN & Recommended Actions \\
\hline \multirow{2}{*}{ Potentiometer } & Bad installation & Lack of speed control & \multirow[b]{2}{*}{7} & Installation mistakes & \multirow{2}{*}{2} & \multirow{2}{*}{$\begin{array}{l}\text { Install components } \\
\text { correctly, allow proper } \\
\text { cooling }\end{array}$} & \multirow{2}{*}{7} & \multirow{2}{*}{98} & Verify correct installation \\
\hline & Heating & Damaged or burnt components & & Risk of short circuit & & & & & Turn off rheometer and allow cooling \\
\hline \multirow{3}{*}{ LCD display } & Burn & $\begin{array}{l}\text { Error in the speed indicated on the } \\
\text { LCD display }\end{array}$ & \multirow{3}{*}{6} & Short circuit & \multirow{3}{*}{4} & \multirow{3}{*}{$\begin{array}{l}\text { Protect it from falls and } \\
\text { water contact }\end{array}$} & \multirow{3}{*}{1} & \multirow{3}{*}{24} & Only connect at the time of testing \\
\hline & Break & Does not turn on the LCD display & & Falls, blows, misuse & & & & & Avoid hitting the LCD display \\
\hline & Short circuit & Does not turn on the LCD display & & Electric shock, overheating & & & & & Protect against humidity \\
\hline \multirow{3}{*}{ Battery holder } & Electrical discharge & \multirow{2}{*}{ No electric power } & \multirow{3}{*}{8} & No electric power & \multirow{3}{*}{5} & \multirow{3}{*}{$\begin{array}{l}\text { Use properly, protect } \\
\text { from the humidity } \\
\text { and clean }\end{array}$} & \multirow{3}{*}{5} & \multirow{3}{*}{200} & Check electrical connection \\
\hline & Incorrect Electrical Wiring & & & Poorly connected wires & & & & & Check wiring and connection \\
\hline & Short circuit & The other components are put at risk & & overheating, contact with water & & & & & $\begin{array}{l}\text { Protecting it from humidity and proper } \\
\text { use }\end{array}$ \\
\hline \multirow[t]{2}{*}{ USB port } & Installation mistakes & $\begin{array}{l}\text { Disconnected USB } \\
\text { Data is not saved }\end{array}$ & \multirow[t]{2}{*}{4} & \multirow[t]{2}{*}{ Bad connection of the USB ports } & \multirow[t]{2}{*}{2} & \multirow[t]{2}{*}{ Replacing components } & \multirow[t]{2}{*}{6} & \multirow[t]{2}{*}{48} & Verify correct installation \\
\hline & Problem with the interface & Data is not saved & & & & & & & Remove and reinsert it \\
\hline \multirow{2}{*}{ Control Panel } & Installation mistakes & lack of control over functions & \multirow[b]{2}{*}{7} & Not installing the component correctly & \multirow{2}{*}{2} & \multirow{2}{*}{$\begin{array}{l}\text { Control panel for } \\
\text { rheometer control }\end{array}$} & \multirow{2}{*}{5} & \multirow{2}{*}{70} & Verify correct installation \\
\hline & Component failure & Difficulty in pressing buttons & & Poor installation, disconnected wires & & & & & Verify correct installation \\
\hline
\end{tabular}

$S$ : Severity; O: Occurrence; $D$ : Detectability. 
The results from the FMEA and the relevant scores for the parameters $\mathrm{S}, \mathrm{O}$, and $\mathrm{D}$ were established to find the RPN of each rheometer component and its characteristic failure modes. The risk assessment was performed on both the mechanical parts and the electrical or electronic components. With the FMEA, it was discovered that the high RPN of 400 corresponds to the electric motor that transmits the torque and rotational movement to the shaft, suggesting that preventive maintenance during operation should be considered a high priority. Another element with a high RPN is the battery case, with a value of 200, which feeds electrical energy to some electronic components, and therefore should be protected from vibrations, falls, or contact with liquid. According to Table 2, these two RPN values classify the failures of these elements as serious or dangerous. With RPN values of 98,80 , and 70, the potentiometer, rotor, and panel or display failure modes are classified as significant failures. The other failure modes fall into the minor category.

\subsection{Finite Element Analysis (FEA)}

This section describes the Finite Element Analysis carried out on the parts that comprise the rheometer, with the objective of verifying if they meet the various established design parameters established and detecting possible improvements to the proposed design. It is worth noting that only a vibration analysis was carried out, as this is a phenomenon that greatly affects the rheometer performance through high-magnitude resonant vibrations [46]. Modal vibration analysis generates the fundamental vibration frequencies of the elements and the magnitude of their deformation.

The ANSYS Workbench software was used for the modal analysis of the rheometer components. The 3D models of the rheometer elements were built in a computer-aided design (SolidWorks) system and imported into the ANSYS Workbench preprocessing platform. The main materials used for the component analysis were structural steel and Nylamid. Steel was assigned a density property of $7850 \mathrm{~kg} / \mathrm{m} 3$, a Young's modulus of $200 \mathrm{GPa}$, and a Poisson's ratio of 0.3; for Nylamid, it was assigned a density of $7850 \mathrm{~kg} / \mathrm{m} 3$, a Young's modulus of $2353 \mathrm{Mpa}$, and a Poisson's ratio of 0.21 . Once the materials were defined, each of the elements analyzed underwent the meshing or discretization process. The finite element SOLID185 was used for the meshing, defined by eight nodes with three degrees of freedom in each node (UX, UY, and UX) [47]. This type of finite element is suitable for modeling general 3D solid structures, allowing prismatic and tetrahedral degenerations. SOLID185 is appropriate for modal analysis, with an adequate ratio of convergence time and computational resource consumption [48]. The mesh convergence test was performed to determine the optimal mesh size using the first modal frequency as a reference. The boundary conditions and speed loads were applied specifically for each case. Modal analysis was limited to the earliest vibration modes, those closest to the rheometer operating speed.

A simulation was carried out on the full rotor (shaft, flywheel, and tip) and the coupling to the driving motor. Figure 6 shows both the meshed geometry and the shape rotor vibration that occurs at the fundamental vibration frequency of $1689.3 \mathrm{~Hz}$. Vibration resonance exists when the frequency of an excitation source coincides with the fundamental frequency of a body or element-an undesirable condition which generates the greatest number of deformations and displacement in bodies. Figure 6 indicates that if there were resonance, the maximum displacements would be at the tip of the shaft where the probe is placed and would be $152.55 \mathrm{~mm}$. The analysis only returns this as a point of design improvement. It is important to mention that the tip is what comes into contact with the sample container, and it would not be appropriate to have those types of vibrations in rheological tests.

Figure 7 shows the result of the analysis of the inertia flywheel, where a fundamental vibrational frequency of $10,026 \mathrm{~Hz}$ was obtained. The shape of resonance vibration and its magnitudes do not represent conditions that require improvement. 


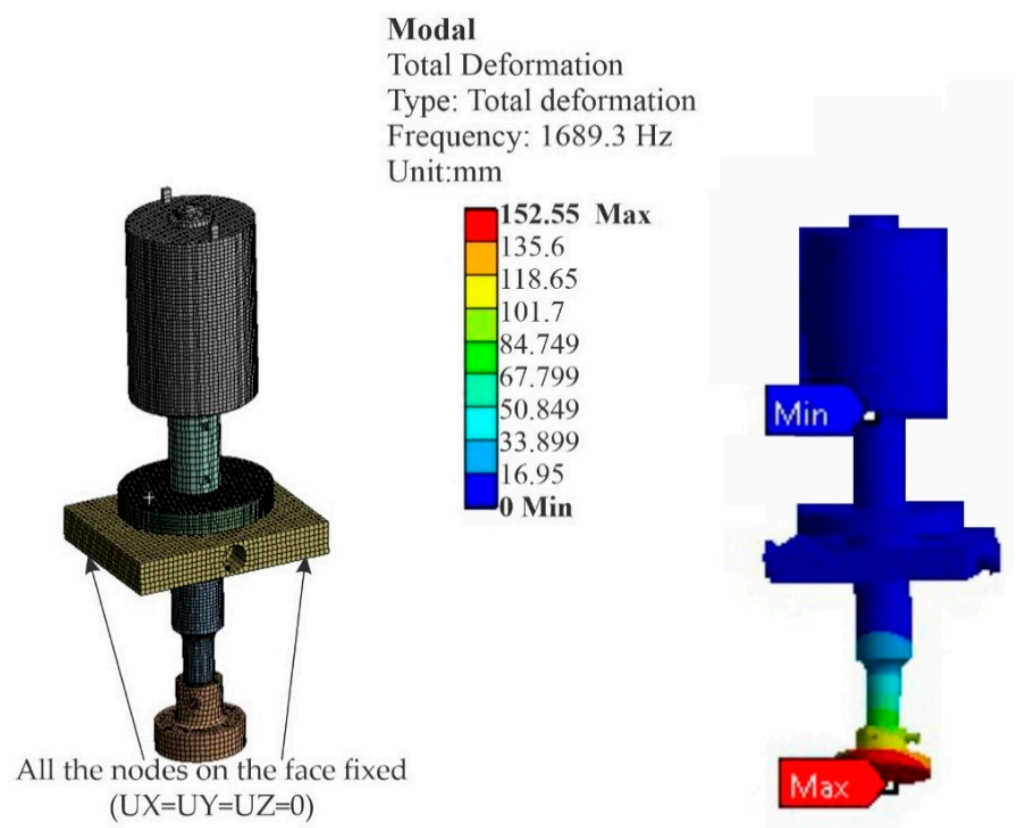

Figure 6. Total deformation of the rotor.

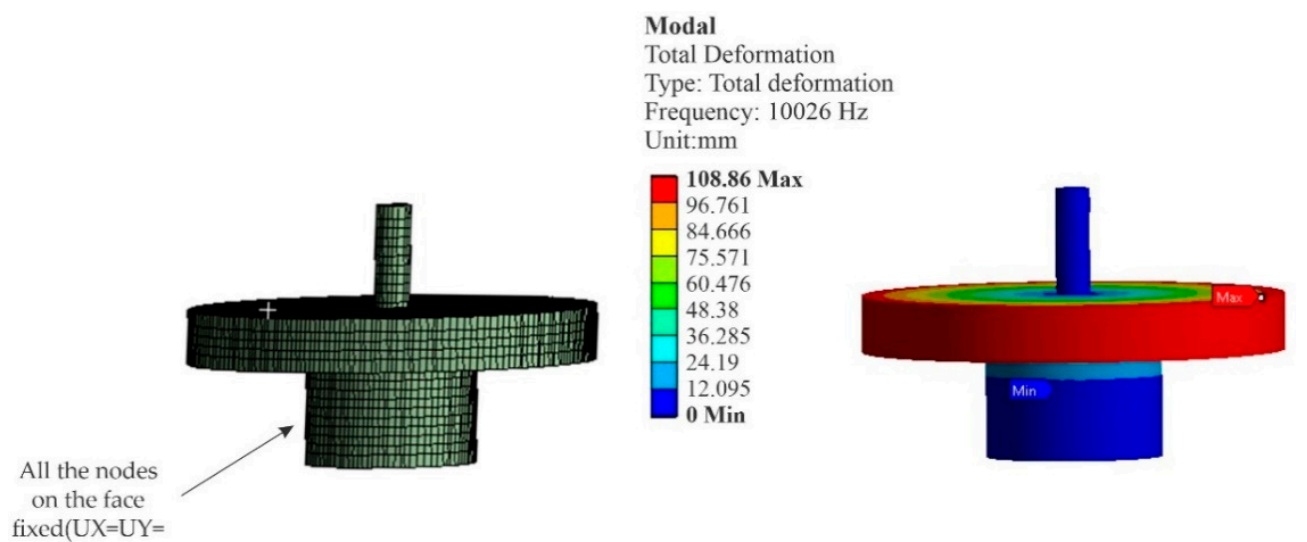

Figure 7. Total deformation of the inertia flywheel.

The tip is the part that is attached to the rotor and is what comes into contact with the fluid. Figure 8 shows the vibration analysis of the shaft and of the tip with the fundamental frequencies of 3928.2 and $28,188 \mathrm{~Hz}$, respectively.

As can be seen by the shapes of the vibration, the tip of the shaft is again in a state of high vibration movements, which is consistent with the rotor analysis findings and is therefore taken into account when making design improvements. Finally, an analysis was carried out on the complete structure, as shown in Figure 9. The fundamental frequency was $331.6 \mathrm{~Hz}$, and resonant displacements of $378.8 \mathrm{~mm}$ were found in the upper rear part of the structure, which indicates that improvements must be made to that section to avoid future performance failures in the rheometer.

With the results from the FMEA and the FEA, the following improvement actions were taken to update the proposed design:

(1) A minimal part or element analysis was performed on the rheometer design. This led to the elimination of some nonessential accessories, helping to meet the requirement of easy maintenance.

(2) Small marks were made on the plates and laminates to increase the stiffness and prevent susceptibility to excessive vibrations and loosening. 
(3) The rotation shaft section was modified at the base, where the test probe is placed, to avoid excessive movements due to vibration based on the results obtained in the FMEA and FEA.

(4) The section of the upper rear part of the structure was modified to avoid movements due to vibration and possible failures caused by mechanical fatigue.

(5) The space devoted to the battery holder for the sensor power source was improved.

(6) Improvements to the electrical components were taken into account in the instrumentation section.

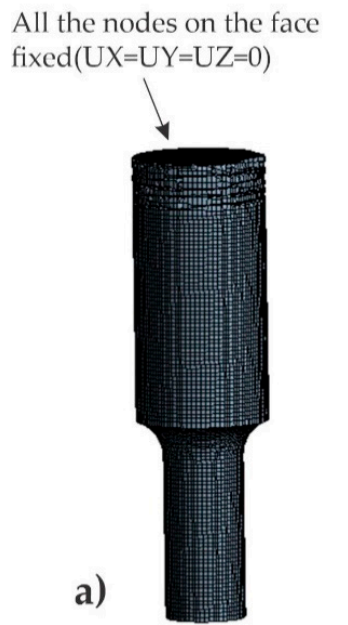

b)

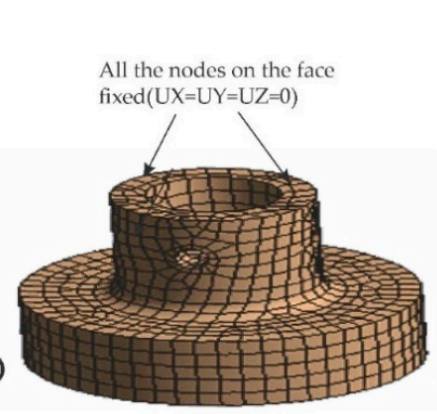

Modal

Total Deformation

Type: Total deformation

Frequency: $3928.2 \mathrm{~Hz}$

Unit:mm

\begin{tabular}{|l}
$\mathbf{2 4 5 . 5 9}$ Max \\
218.3 \\
-191.02 \\
-163.73 \\
136.44 \\
109.15 \\
81.864 \\
54.576 \\
27.288 \\
$\mathbf{0}$ Min
\end{tabular}

Modal

Total Deformation

Type: Total deformation

Frequency: $28188 \mathrm{~Hz}$

Unit:mm

377.83 Max

335.85
293.87

251.89

209.91

167.92

83.962

41.981

0 Min

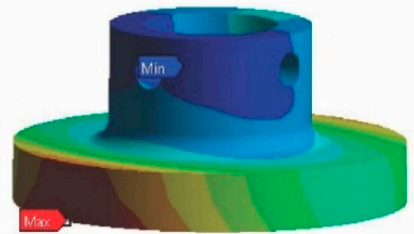

Figure 8. Total deformation-(a) shaft and (b) tip.

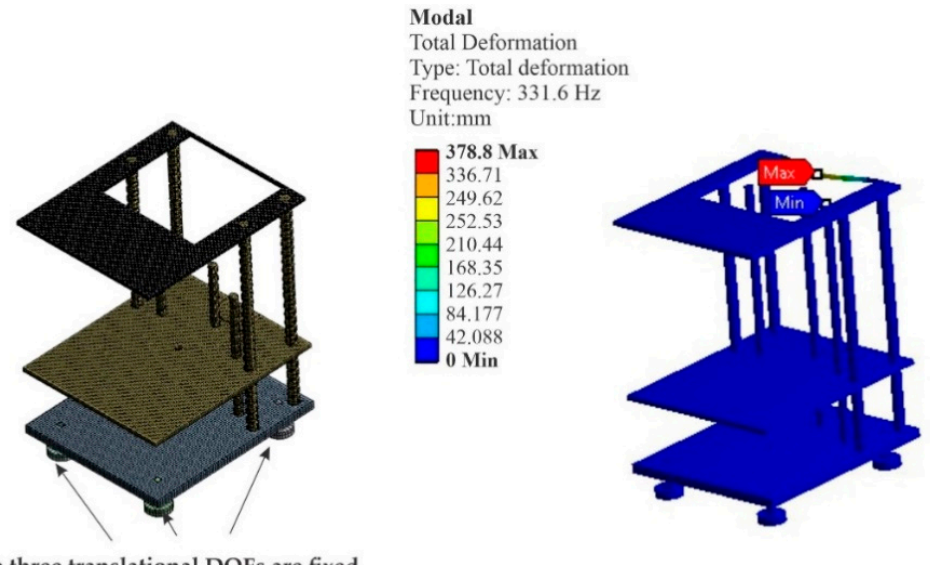

The three translational DOFs are fixed

Figure 9. Total deformation—structure of steel plates and rods.

Figure 10 shows the final rheometer design drawn up in CAD as a result of the improvement points. 

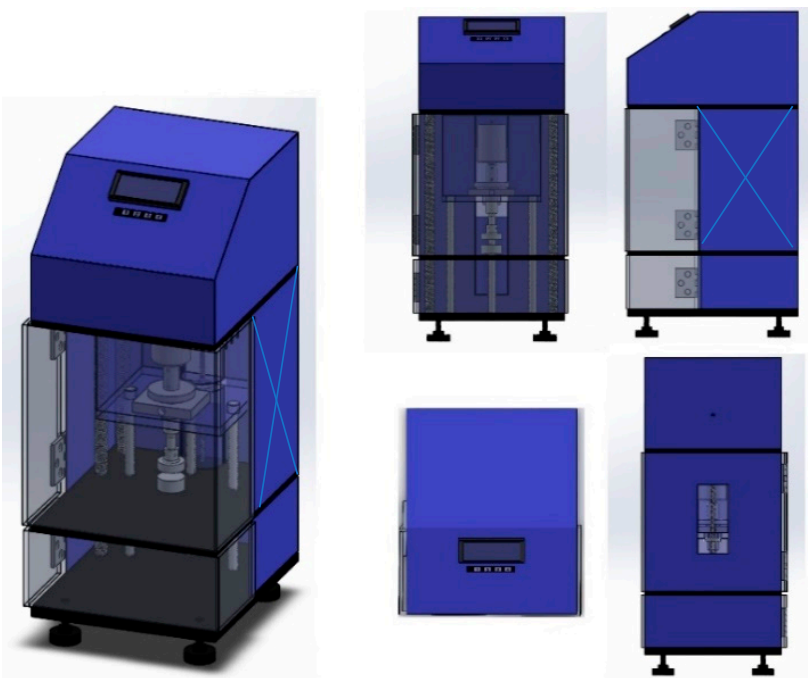

Figure 10. Final rheometer design.

\subsection{Rheometer Manufacturing Process}

Once the final design was finished in CAD, and based on the results from the QFD, FMEA, and FEA, the rheometer was manufactured with materials such as steel, acrylic, aluminum, laminated steel, Nylamid, and stainless steel. The manufacturing planning process and the sequence of features or processes was performed using the process sheet tool with the exact sequence of features necessary to complete the work. A process sheet was completed for each rheometer component. Table 7 shows the process sheet for the sheet metal casing of the rheometer.

Table 7. Sheet process-metal casing.

\begin{tabular}{|c|c|c|c|c|}
\hline \multirow{2}{*}{$\begin{array}{c}\text { Control } \\
\text { Manufacturing } \\
\text { Processes (CMP) }\end{array}$} & \multirow{2}{*}{\multicolumn{3}{|c|}{$\begin{array}{c}\text { Sheet Process } \\
\text { "Sheet Metal Casing" }\end{array}$}} & Part: 9 \\
\hline & & & & Sheet: 9 \\
\hline $\begin{array}{c}\text { Title } \\
\text { Sheet Metal Casing }\end{array}$ & Material Galvanized Sheet & $\begin{array}{l}\text { Dime } \\
300 \times 2 \\
160 \times\end{array}$ & $\begin{array}{l}\text { ons } \\
\mathrm{mm} \\
\mathrm{mm}\end{array}$ & $\begin{array}{l}\text { Estimated Time } \\
\quad 1 \mathrm{~h} 30 \mathrm{~min} .\end{array}$ \\
\hline Op. & Description & Tools and Equipment & Working Conditions & Estimated Operation Time \\
\hline 1 & Trace the dimensions on the cardboard sheets & Tape measure and square & Manual & $20 \mathrm{~min}$. \\
\hline 2 & $\begin{array}{l}\text { Using the cardboard, mark the exact } \\
\text { measurements on the galvanized Sheet }\end{array}$ & Square and marker & Manual & $10 \mathrm{~min}$. \\
\hline 3 & $\begin{array}{l}\text { Cut the galvanized sheet according to the } \\
\text { proposed measurements }\end{array}$ & Sheet metal scissors & Manual & $10 \mathrm{~min}$. \\
\hline 4 & Drill holes in the galvanized sheet & Drill and bit set & Manual & $15 \mathrm{~min}$. \\
\hline 5 & $\begin{array}{l}\text { Bend the galvanized sheet to the proposed } \\
\text { dimensions }\end{array}$ & Hydraulic bending press & Manual & $10 \mathrm{~min}$. \\
\hline 6 & Weld the indicated flaps of the galvanized sheet & Automatic spot welder & Manual & $15 \mathrm{~min}$. \\
\hline 7 & Sand the galvanized sheet & $\begin{array}{l}\text { Sponge sanding pads } \\
\text { and ultra fine sand paper }\end{array}$ & Manual & $10 \mathrm{~min}$. \\
\hline 8 & Painting galvanized sheet & Air paint gun & Manual & $20 \mathrm{~min}$. \\
\hline
\end{tabular}

Figure 11 shows some elements of the manufactured rheometer. 


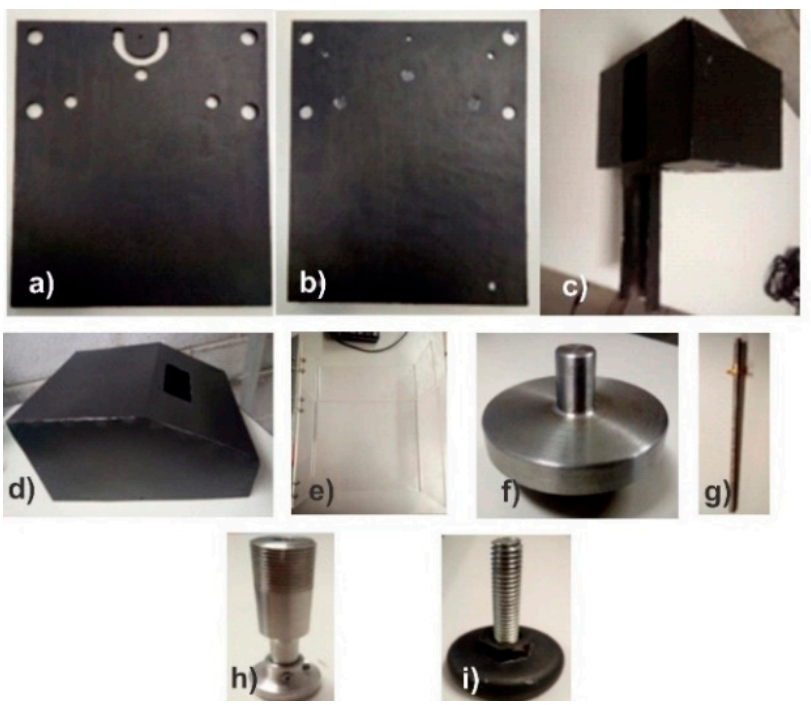

Figure 11. (a) and (b) Steel plates, (c) container box (the motor and electronic accessories), (d) sheet metal casing, (e) acrylic protective cover, (f) inertia flywheel, (g) threaded rod, (h) rotor (shaft ant tip), (i) adjustable leg leveler.

With the components manufactured, the structure assembly process is developed, as shown in Figure 12.

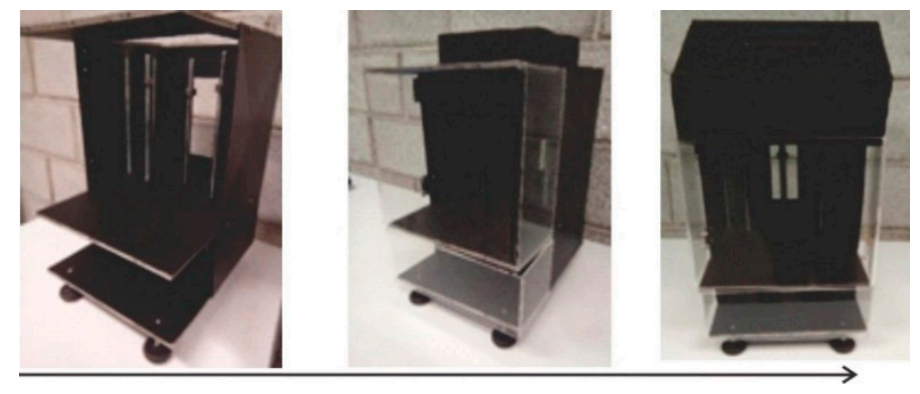

Figure 12. Structure assembly process.

The internal part of the rheometer is composed of the motor (12V DC-RPM: 1000RPM) and its accessories. Figure 13 shows the complete assembly, which is composed of the rotor, couplings, bearings, and inertia flywheel. This assembly is particularly important for the rheological testing process.
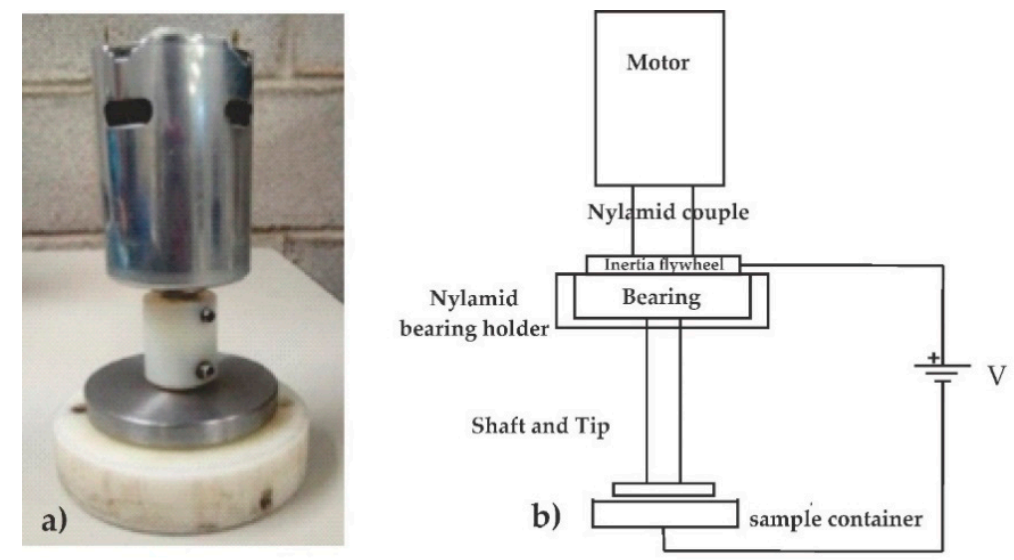

Figure 13. (a) Motor and inertia flywheel assembly, (b) electrical arrangement for electromechanical tests. 
The Nylamid elements were included to isolate the motor and the electrical and electronic components from the energy used for the electro-rheological tests (Figure 13b).

\subsection{Instrumentation and Implementation}

To meet customer requirements regarding the environment or user interaction with the rheometer, it was decided to use the Arduino platform to manage the sensors, button panel, display, automatic software calculations, and storage of the test data. Some devices used in the instrumentation of the rheometer include the following:

(a) Open platform Arduino UNO boards, which facilitate microcontroller programming.

(b) A DHT11 digital temperature and humidity sensor, which uses a capacitive humidity sensor and a thermistor to measure the surrounding air and only one pin to read the data.

(c) An FC-03 Infrared Sensor Encoder, a device responsible for converting angular movement into electrical pulses which can be interpreted by the system controller.

(d) An Arduino button panel, control element.

(e) An H Bridge L298N, a circuit that allows controlling the direction of the rotation and speed in DC motors.

(f) An LCD display and an I2C Adapter for LCD displays with microcontrollers.

The separation of the parallel plates from the tip is measured from the vertical displacement bar, and the torque is estimated based on the current and intake voltage of the driving motor.

Figure 14 shows the tests carried out on the sensors.

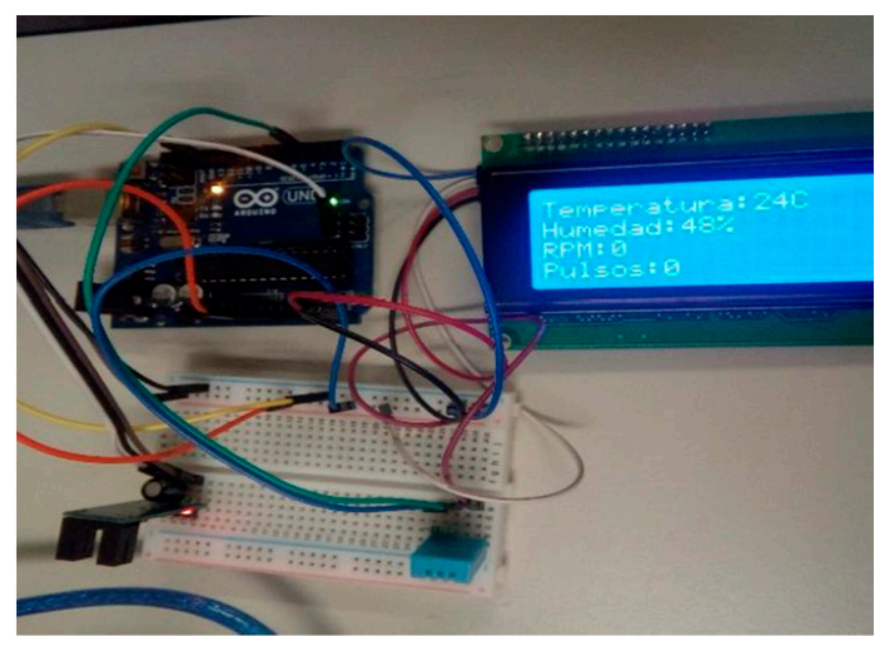

Figure 14. Sensor and LCD display testing.

Finally, the assembly of the rheometer is completed, as shown in Figure 15. 

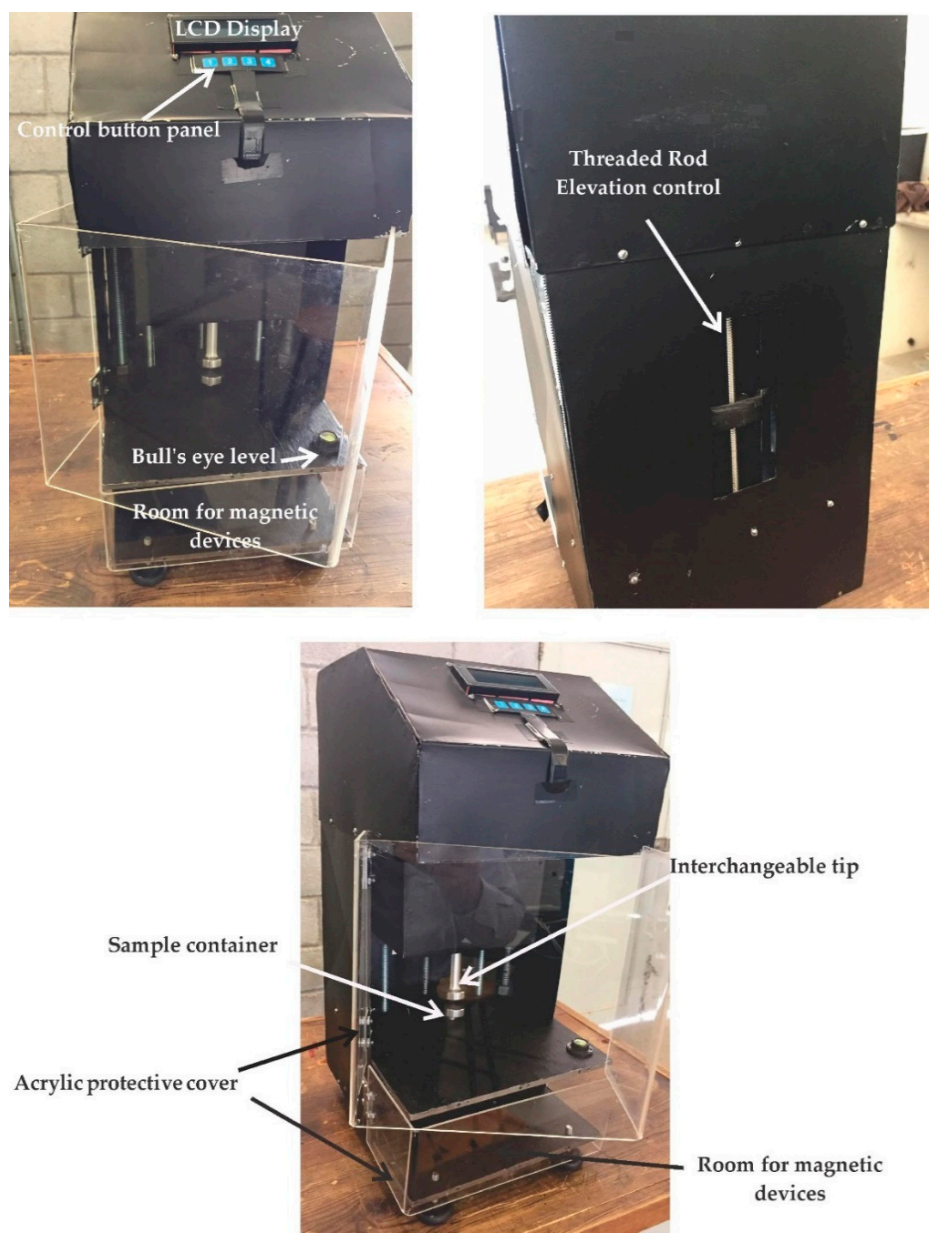

Figure 15. Manufactured rheometer-final version. Product specifications: power source 110V, sensor power source $12 \mathrm{~V}$, variable speed operation from 0 to $1000 \mathrm{RPM}$, interchangeable test probes, ability to incorporate attachments to perform electro- and magneto-rheological tests.

\section{Discussion}

The main interest of this work was accomplished by obtaining a rotational rheometer with the required characteristics using of the methodologies set forth herein. By developing the QFD by means of the matrices in the aforementioned House of Quality, it was possible to guide this work toward the rheometer design and manufacturing stages. To manufacture the prototype, it was necessary to determine the customer, technical, or engineering requirements and establish the correlation between these. The accuracy of the customer requirements depends on the work team's environment, in addition to its knowledge and experience in the subject. In this regard, the work team had to overcome the lack of contributions from more people or customers, as rheometers are not commonly used instruments and their application is very specialized. However, with the help of research into patents and scientific articles, the customer's significant requirements were met to structure the House of Quality. Another aspect detected during the QFD elaboration process was weakness or subjectivity when performing the benchmarking, as an additional, more reliable mechanism is required to make this judgement and achieve greater reliability and determination [23]. Rheometer performance and cost are highly valued aspects on the market. The rheometer designed and built in this work has a material and supply cost of \$1500 USD, not including labor-a very competitive price in comparison to commercial rheometers. 


\section{Limitations and Expected Impact}

Improvements in the rheometer development process presented in this work arise from the analysis with the following limitations:

- The sample of participants considered for the requirements analysis and for the design process should be improved, involving more experts in the field of rheology, equipment vendors, users, and analysts.

- Although the methodology used in the preliminary design stage was sufficient to fulfill the objective of this work, more robust or systematic methods for the entire preliminary design process need to be adopted, as suggested by some research works in the field of design [37,49].

- A weakness found during the stage is the lack of an in-depth analysis of the technical details in the design of the proposed solution.

- It would be very convenient to update the failure mode analysis (FMEA) with field evaluations of the experimental performance in order to continue improving and adjusting the rheometer design.

- The verification stage of the experimental operation of the rheometer would give certainty for industrial production and would give feedback on the entire design process.

- An ergonomic analysis of man-machine interaction would undoubtedly strengthen the development process of the rheometer as a product.

We consider that the main impact of this work is the development of a low-cost rheometer using technology within the reach of most people, not only in the industrial sector. The implemented methodology is already well known, but it can be followed for the development of other equipment or instruments. Academically, having a rheometer like the one developed in this work will impact research in the field of rheology and will support the training of future engineering students.

\section{Conclusions}

The low-cost rotational rheometer developed in this study was achieved using quality control and continuous improvement tools, such as QFD-HoQ and FMEA, in addition to the use of manufacturing tools such as Manufacturing Process Management and engineering CAE tools such as the FEA. The rheometer design has the capacity to adapt in order to perform both electro- and magneto-rheological tests. During the design and construction process, the design team adhered to the customer's requirements and to the engineering requirements proposed, taking the advantage offered by the QFD. In addition, improvements in the proposed rheometer design were achieved with the FMEA technique in order to detect any possible failures and the development of an engineering analysis (FEA) to ensure the design in the structural part and the operation with which the rheometer construction was finally achieved. With the results obtained in this study, the possibility of designing rheometers was left open for electro- and magneto-rheological tests in the future.

Author Contributions: Conceptualization, F.J.H.-R., P.C.-A., and J.M.-M.; resources and materials, M.Z.S.-L., J.M.R.-L., and V.A.R.-H.; writing-original draft preparation, P.C.-A. and H.B.-S.; writing and analysis, P.C.-A. and J.M.-M.; writing-review and editing, P.C.-A. and H.B.-S. All authors have read and agreed to the published version of the manuscript.

Funding: This research received no external funding.

Acknowledgments: The authors gratefully acknowledge mechanical engineering student Elsa Guadalupe Salas Reyes for her participation in the development of this work.

Conflicts of Interest: The authors declare no conflict of interest.

\section{References}

1. Schramm, G. A Practical Approach to Rheology and Rheometry; Block, H., Kelly, J.P., Eds.; Gebrueder Haake: Karlsruhe, Germany, 1994. 
2. Barnes, H.A.; Hutton, J.F.; Walters, K. An Introduction to Rheology; Rheology Series; Elsevier Science Publishers: Amsterdam, The Netherlands, 1989.

3. Halsey, T.C.; Toor, W. Structure of electrorheological fluids. Phys. Rev. Lett. 1990, 65, 2820-2823. [CrossRef] [PubMed]

4. García-Ortiz, J.H.; Sadek, S.H.; Galindo-Rosales, F.J. Influence of the Polarity of the Electric Field on Electrorheometry. Appl. Sci. 2019, 9, 5273. [CrossRef]

5. Lang, L.; Alexandrov, S.; Lyamina, E.; Dinh, V.M. The Behavior of Melts with Vanishing Viscosity in the Cone-and-Plate Rheometer. Appl. Sci. 2020, 10, 172. [CrossRef]

6. Wang, H.; Jiao, J.; Wang, Y.; Du, W. Feasibility of Using Gangue and Fly Ash as Filling Slurry Materials. Processes 2018, 6, 232. [CrossRef]

7. Wang, H.; Hassan, E.A.M.; Memon, H.; Elagib, T.H.H.; Abad AllaIdris, F. Characterization of Natural Composites Fabricated from Abutilon-Fiber-Reinforced Poly (Lactic Acid). Processes 2019, 7, 583. [CrossRef]

8. De la Cruz Martínez, A.; Delgado Portales, R.E.; Pérez Martínez, J.D.; González Ramírez, J.E.; Villalobos Lara, A.D.; Borras Enríquez, A.J.; Moscosa Santillán, M. Estimation of Ice Cream Mixture Viscosity during Batch Crystallization in a Scraped Surface Heat Exchanger. Processes 2020, 8, 167. [CrossRef]

9. Li, D.; Li, G.; Chen, Y.; Man, J.; Wu, Q.; Zhang, M.; Chen, H.; Zhang, Y. The Impact of Erythrocytes Injury on Blood Flow in Bionic Arteriole with Stenosis Segment. Processes 2019, 7, 372. [CrossRef]

10. Wang, Y.; Huang, Y.; Hao, Y. Experimental Study and Application of Rheological Properties of Coal Gangue-Fly Ash Backfill Slurry. Processes 2020, 8, 284. [CrossRef]

11. García-Ortiz, J.H.; Galindo-Rosales, F.J. Extensional Magnetorheology as a Tool for Optimizing the Formulation of Ferrofluids in Oil-Spill Clean-Up Processes. Processes 2020, 8, 597. [CrossRef]

12. Huang, W.; Wang, D.; He, P.; Long, X.; Tong, B.; Tian, J.; Yu, P. Rheological Characteristics Evaluation of Bitumen Composites Containing Rock Asphalt and Diatomite. Appl. Sci. 2019, 9, 1023. [CrossRef]

13. Cruz, P.; Martínez, F.J.; Pineda, Z.; Morales, J.; Hernández, J.F.; Reyes, M.; Figueroa, R.A. Perspectiva del uso de amortiguadores inteligentes en vehículos eléctricos. In Tendencias Actuales de Fuentes de Energía Renovables; UASLP: Matehuala, México, 2017; pp. 26-31. ISBN 978-607-535-017-2.

14. Pineda, R.Z.; Martínez, L.F.J.; Cruz, A.P. Amortiguadores inteligentes y reología. Univ. Potos. 2017, 216, 28-33.

15. Zapateiro, M.; Pozo, F.; Karimi, H.R.; Luo, N. Semiactive Control Methodologies for Suspension Control with Magnetorheological Dampers. IEEE/ASME Trans. Mechatron. 2012, 17, 370-380. [CrossRef]

16. da Silva, V.B.; da Costa, M.P. Influence of Processing on Rheological and Textural Characteristics of Goat and Sheep Milk Beverages and Methods of Analysis. In Processing and Sustainability of Beverages; Grumezescu, A.M., Holban, A.M., Eds.; Woodhead Publishing: Sawston, Cambridge, 2019; pp. 373-412. ISBN 9780128152591. [CrossRef]

17. Akao, Y. Development history of quality function deployment. In The Customer Driven Approach to Quality Planning and Deployment; Asian Productivity Organization: Minato, Tokyo, Japan, 1994.

18. Kuijt-Evers, L.F.M.; Morel, K.P.N.; Eikelenberg, N.L.W.; Vink, P. Application of the QFD as a design approach to ensure comfort in using hand tools: Can the design team complete the House of Quality appropriately? Appl. Ergon. 2009, 40, 519-526. [CrossRef] [PubMed]

19. Utne, I.B. Improving the environmental performance of the fishing fleet by use of Quality Function Deployment (QFD). J. Clean. Prod. 2009, 17, 724-731. [CrossRef]

20. Elena, F.; Gazizulina, A.; Eskina, E.; Ostapenko, M.; Aidarov, D. Development of QFD Methodology. In Quality, IT and Business Operations; Springer Proceedings in Business and Economics; Kapur, P., Kumar, U., Verma, A., Eds.; Springer: Singapore, 2018.

21. Tan, X.; Xiong, W. Improving Product Quality Based on QFD and FMEA Theory. In 2020 Prognostics and Health Management Conference (PHM-Besançon); IEEE: Besancon, France, 2020; pp. 274-282. [CrossRef]

22. Mukherjee, S.P. Improving Process Quality. In Quality. India Studies in Business and Economics; Springer: Singapore, 2019; ISBN 978-981-13-1270-0. [CrossRef]

23. Franceschini, F.; Maisano, D. A new proposal to improve the customer competitive benchmarking in QFD. J. Qual. Eng. 2018, 30, 730-761. [CrossRef]

24. Freddi, A.; Salmon, M. Design Principles and Methodologies from Conceptualization to First Prototyping with Examples and Case Studies; Springer International Publishing: Cham, Switzerland, 2019; ISBN 978-3-319-95341-0. 
25. Almannai, B.; Greenough, R.; Kay, J. A decision support tool based on QFD and FMEA for the selection of manufacturing automation technologies. Robot. Comput.-Integr. Manuf. 2008, 24, 501-507. [CrossRef]

26. Zadry, H.R.; Rahmayanti, D.; Susanti, L.; Fatrias, D. Identification of Design Requirements for Ergonomic Long Spinal Board Using Quality Function Deployment (QFD). Procedia Manuf. 2015, 3, 4673-4680. [CrossRef]

27. Marsot, J. QFD: A methodological tool for integration of ergonomics at the design stage. Appl. Ergon. 2005, 36, 185-192. [CrossRef]

28. Mayda, M.; Choi, S. A reliability-based design framework for early stages of design process. J. Braz. Soc. Mech. Sci. Eng. 2017, 39, 2105-2120. [CrossRef]

29. Wolniak, E.R.; Sȩdek, A. Using QFD method for the ecological designing of products and services. Qual. Quant. 2009, 43, 695-701. [CrossRef]

30. Trafialek, J.; Kolanowski, W. Application of Failure Mode and Effect Analysis (FMEA) for audit of HACCP system. Food Control 2014, 44, 35-44. [CrossRef]

31. Liu, H.; Deng, X.; Jiang, W. Risk Evaluation in Failure Mode and Effects Analysis Using Fuzzy Measure and Fuzzy Integral. Symmetry 2017, 9, 162. [CrossRef]

32. Zheng, Y.; Johnson, R.; Larson, G. Minimizing treatment planning errors in proton therapy using failure mode and effects analysis. Int. J. Radiat. Oncol. Biol. Phys. 2016, 43, 2904-2910. [CrossRef] [PubMed]

33. Manger, R.P.; Paxton, A.B.; Pawlicki, T.; Kim, G.Y. Failure mode and effects analysis and fault tree analysis of surface image guided cranial radiosurgery. Med. Phys. 2015, 42, 2449-2461. [CrossRef] [PubMed]

34. Kim, K.M.; Yun, N.; Yun, H.J.; Dong, H.L.; Cho, H.H. Failure analysis in after shell section of gas turbine combustion liner under base-load operation. Eng. Fail. Anal. 2010, 17, 848-856. [CrossRef]

35. Fiorineschi, L.; Becattini, N.; Borgianni, Y.; Rotini, F. Testing a New Structured Tool for Supporting Requirements' Formulation and Decomposition. Appl. Sci. 2020, 10, 3259. [CrossRef]

36. Kroll, E. Design theory and conceptual design: Contrasting functional decomposition and morphology with parameter analysis. Res. Eng. Des. 2013, 24, 165-183. [CrossRef]

37. Pahl, G.; Beitz, W.; Feldhusen, J.; Grote, K.H. Engineering Design, 3rd ed.; Springer: London, UK, 2007. [CrossRef]

38. Jinks, T. The 5W1H Method. In Psychological Perspectives on Reality, Consciousness and Paranormal Experience; Palgrave Macmillan: Cham, Switzerland, 2019. [CrossRef]

39. Altshuller, G. Creativity as an Exact Science: The Theory of the Solution of Inventive Problems; Gordon and Breach Science Publishing: New York, NY, USA, 1984; ISBN 0-677-21230-5.

40. Yamashina, H.; Ito, T.; Kawada, H. Innovative product development process by integrating QFD and TRIZ. Int. J. Prod. Res. 2002, 40, 1031-1050. [CrossRef]

41. Whiteley, M.; Dunnett, S.; Jackson, L. Failure Mode and Effect Analysis, and Fault Tree Analysis of Polymer Electrolyte Membrane Fuel Cells. Int. J. Hydrog. Energy 2016, 41, 1187-1202. [CrossRef]

42. Hughes, T.J.R. The Finite Element Method: Linear Static and Dynamic Finite Element Analysis, 1st ed.; Dover Publications: Mineola, NY, USA, 2000; ISBN 978-0486411811.

43. Strang, G.; Fix, G.J. An Analysis of the Finite Element Method, 2nd ed.; Series in Automatic Computation; Prentice-Hall, Inc.: Englewood Clifs, NJ, USA, 1973.

44. Zhang, H.C. Manufacturing Process Planning. In Handbook of Automation and Manufacturing System; Dorf, R.C., Kusiak, A., Eds.; John Wiley \& Sons: New York, NY, USA, 1994; pp. 587-616. ISBN 978-0-471-55218-5.

45. Swamidass, P.M. Encyclopedia of Production and Manufacturing Management; Springer: New York, NY, USA, 2000; p. 980. ISBN 978-0-7923-8630-8. [CrossRef]

46. Ouriev, B.N.; Uriev, N.B. Influence of vibration on structure rheological properties of a highly concentrated suspension. Meas. Sci. Technol. 2005, 16, 1691-1700.

47. ANSYS Mechanical APDL Element Reference; ANSYS, Inc.: Canonsburg, PA, USA, 2011.

48. ANSYS Meshing User's Guide; ANSYS, Inc.: Canonsburg, PA, USA, 2013.

49. Fiorineschi, L.; Papini, S.; Pugi, L.; Rindi, A.; Rotini, F. Systematic design of a new gearbox for concrete mixers. J. Eng. Des. Technol. 2020. [CrossRef]

(C) 2020 by the authors. Licensee MDPI, Basel, Switzerland. This article is an open access article distributed under the terms and conditions of the Creative Commons Attribution (CC BY) license (http://creativecommons.org/licenses/by/4.0/). 